\title{
Opioid rotation with extended-release opioids: where should we begin?
}

This article was published in the following Dove Press journal:

International Journal of General Medicine

29 December 201I

Number of times this article has been viewed

\section{Srinivas Nalamachu \\ International Clinical Research Institute and Pain Management Institute, Overland Park, KS, USA}

Correspondence: Srinivas Nalamachu International Clinical Research Institute, I I 20 Tomahawk Creek Parkway, Overland Park, KS 662II, USA

$\mathrm{Tel}+\mathrm{I} 9133175300$

Fax +19133175301

Email nalamachu@yahoo.com
Abstract: Opioid rotation is a common and necessary clinical practice in the management of chronic non-cancer pain to improve therapeutic efficacy with the lowest opioid dose. When dose escalations fail to achieve adequate analgesia or are associated with intolerable side effects, a trial of a new opioid should be considered. Much of the scientific rationale of opioid rotation is based on the wide interindividual variability in sensitivity to opioid analgesics and the novel patient response observed when introducing an opioid-tolerant patient to a new opioid. This article discusses patient indicators for opioid rotation, the conversion process between opioid medications, and additional practical considerations for increasing the effectiveness of opioid therapy during a trial of a new opioid. A Patient vignette that demonstrates a step-wise approach to opioid rotation is also presented.

Keywords: extended-release opioids, chronic pain, opioid rotation

\section{Introduction}

Patients treated with opioid analgesics exhibit broad differences in sensitivity to the analgesic and nonanalgesic effects of these medications. ${ }^{1}$ Such differences necessitate a highly individualized approach to therapy, with the goal of balancing the therapeutic effects with the side effects. When dose escalations are associated with inadequate analgesia or intolerable side effects, a planned switch from one opioid to another opioid can be considered. ${ }^{2-4}$ This treatment approach, known as "opioid rotation," is a common clinical practice intended to improve a patient's response to treatment. ${ }^{3}$ Rotating to a new opioid may be necessary at any time after the initiation of therapy. Clinical guidelines recommend opioid rotation for patients with chronic pain who experience a decline in therapeutic efficacy with their current opioid, or for patients who experience inadequate efficacy or intolerable adverse events (AEs) during dose titration. ${ }^{2}$

The rationale for opioid rotation is based on the wide interindividual variability in sensitivity to opioid analgesics and the novel patient response observed when introducing an opioid-tolerant patient to a new opioid. ${ }^{1,2,4,5}$ Specifically, patients may respond very differently with respect to analgesic and nonanalgesic effects (eg, adverse effects). ${ }^{5}$ This variability is the outcome of a complex interaction between drug-related and biological factors. ${ }^{4,5}$ The differential activities of opioid analgesics are determined, at least in part, by the relative binding affinities to the different opioid receptor classes and subtypes. Opioids used for moderate-to-severe chronic non-cancer pain exert their analgesic effects primarily via mu-opioid receptors, and some data exist for the 
existence of different subtypes of mu-opioid receptors. ${ }^{6,7}$ Accordingly, a patient who has displayed marked tolerance to one opioid may display incomplete cross-tolerance to another opioid with a different receptor-binding profile. ${ }^{8,9}$ This can be manifested clinically as a restoration of analgesic sensitivity upon administration of a different opioid. Individual variation in receptor distribution and sensitivity likely influences the wide range of doses required to obtain adequate analgesia with a given opioid. Theoretically, matching the patient with the proper mu-opioid receptor agonist will allow patients to obtain adequate analgesia with tolerable AEs at the lowest possible dose.

Commonly used opioids for managing moderate-to-severe chronic non-cancer pain include immediate-release (IR) and extended-release (ER) formulations of hydromorphone, morphine sulfate, oxycodone, oxymorphone, and tapentadol, as well as transdermal fentanyl. ${ }^{10-19}$ Treatment strategies to manage this type of pain include combinations of an ER and IR opioid to provide baseline and supplemental analgesia for breakthrough pain. ${ }^{2}$ The selection of the opioid should take into account such factors as the patient's medical status, age, previous exposure to opioid therapy, and access to medication, as well as cost and convenience of administration. ${ }^{2,4}$ The patient's likelihood for misuse, abuse, and overdose should also factor in the treatment decision. ${ }^{20}$ Regardless of which opioid is selected, patients will likely require rotation to a new opioid at some point during treatment to maintain analgesic efficacy. The following discussion provides an approach to implement opioid rotation in patients with chronic non-cancer pain, as well as clinical considerations in the practical management of patients undergoing opioid rotation. In addition, a Patient vignette is presented to illustrate key decision points in opioid rotation.

\section{Approach to opioid rotation Deciding when to initiate opioid rotation}

Attempts at dose escalation often precede opioid rotation, as this is a logical next step for pain patients experiencing inadequate analgesia with their current opioid dose. ${ }^{2,3}$ However, the clinical utility of administering higher opioid doses is limited by several factors, including an increase of treatment-related AEs (ie, nausea, constipation, somnolence)..$^{2,10-17}$ In addition, no current standard definition for a "high dose" exists, and there is a lack of substantial evidence-based guidance for safe prescribing practices at higher doses. ${ }^{2}$ Furthermore, although there is no theoretical ceiling dose for pure opioid analgesics, ${ }^{2}$ with repeated dose escalation and higher daily opioid doses, there is an increased risk for overdose death. ${ }^{21,22}$ In a study of chronic pain patients, those who received a total daily dose of $\geq 50 \mathrm{mg} /$ day and $\geq 100 \mathrm{mg} /$ day morphine equivalent had an approximately 5- and 7-times greater risk of opioid overdose death compared with patients receiving $<20 \mathrm{mg} /$ day morphine equivalent, respectively. ${ }^{21}$

Patient vignette Opioid Rotation ${ }^{\mathrm{a}}$

\begin{tabular}{|c|c|c|}
\hline \multirow[t]{2}{*}{ Patient } & \multicolumn{2}{|l|}{ 42-year-old patient } \\
\hline & \multicolumn{2}{|c|}{ Primary diagnosis: neuropathic pain from multiple back surgeries for lumbosacral spine disease } \\
\hline \multirow[t]{2}{*}{ Initial opioid treatment } & \multicolumn{2}{|l|}{ Baseline opioid: 40 mg/8 hours oxycodone ER } \\
\hline & \multicolumn{2}{|c|}{ Supplemental analgesic: 5/500 mg hydrocodone IR/APAP, up to 6/day as needed } \\
\hline Rationale for rotation to a & \multicolumn{2}{|l|}{ Inadequate pain control with current medications } \\
\hline new opioid & \multicolumn{2}{|c|}{ Clinician concern over risks associated with total daily dose of APAP } \\
\hline \multirow[t]{2}{*}{ Selected opioid for rotation } & \multicolumn{2}{|l|}{ Baseline opioid: hydromorphone ER } \\
\hline & \multicolumn{2}{|l|}{ Supplemental analgesic: oxycodone IR } \\
\hline \multirow[t]{10}{*}{ Conversion to hydromorphone ER } & \multirow[t]{2}{*}{ Previous total daily dose (baseline opioid): } & $120 \mathrm{mg} /$ day oxycodone ER \\
\hline & & $30 \mathrm{mg} /$ day hydrocodone IR \\
\hline & ER oxycodone morphine equivalent dose: & $240 \mathrm{mg} /$ day \\
\hline & IR hydrocodone morphine equivalent dose: & $60 \mathrm{mg} / \mathrm{day}$ \\
\hline & Total daily morphine equivalent dose: & $300 \mathrm{mg} /$ day \\
\hline & Conversion ratio to hydromorphone $\mathrm{ER}^{\mathrm{b}}$ : & 5:I morphine equivalent:hydromorphone \\
\hline & New total daily dose: & 60 mg/day hydromorphone ER \\
\hline & $\begin{array}{l}\text { Starting dose (with } \sim 50 \% \text { additional reduction } \\
\text { of equianalgesic dose): }\end{array}$ & $32 \mathrm{mg} /$ day $(2 \times 16 \mathrm{mg}$ tablets $)$ hydromorphone $\mathrm{ER}^{\mathrm{c}}$ \\
\hline & \multirow[t]{2}{*}{ Stable opioid dose: } & $48 \mathrm{mg} / \mathrm{day}$ hydromorphone ER titrated over next \\
\hline & & 2 weeks $^{d}$ \\
\hline Outcome & \multicolumn{2}{|c|}{ Well tolerated with adequate around-the-clock pain control } \\
\hline
\end{tabular}

Notes: ${ }^{a}$ This example is taken from the author's experience with one patient during a clinical trial; ' ${ }^{\mathrm{c}}$ linical trials of patients with chronic pain support the efficacy and safety of 5:I morphine equivalent:hydromorphone ER conversion ratio ${ }^{23,24}$; can alternative conversion strategy would be to administer $36 \mathrm{mg} /$ day ( $3 \times 12 \mathrm{mg}$ tablets) hydromorphone ER and titrate to $48 \mathrm{mg} /$ day over the next 2 weeks; ${ }^{\text {dprovided }} 5 \mathrm{mg} /$ day oxycodone IR, up to 3/day as needed for supplemental analgesia.

Abbreviations: ER, extended-release; IR, immediate-release; APAP, acetaminophen. 
For patients maintained on combination opioid products containing acetaminophen (APAP), careful consideration should also be given to unencumbered dose increases. In response to reports of severe liver injury associated with high doses of APAP, the US Food and Drug Administration (FDA) recently limited the amount of APAP in oral combination products to $325 \mathrm{mg} / \mathrm{dose}$, and the total daily dose to $4000 \mathrm{mg} /$ day. $^{25}$ Additional recommendations call to further limit the total daily dose of APAP to $2600 \mathrm{mg} /$ day. ${ }^{26}$

Intolerable AEs or lack of effective analgesia following dose escalation may necessitate rotation to a new opioid (Table 1). ${ }^{2,3}$ It is important to note that this practice is not limited to the introduction of one new opioid, but may be approached as one trial in a sequence of rotations. ${ }^{27} \mathrm{~A}$ lack of analgesia or an increase in AEs with the new opioid might indicate the need for a second, or additional, rotation. ${ }^{4}$ In a retrospective chart review of chronic pain patients prescribed long-acting or ER opioids, the cumulative percentage of patients who achieved an effective, well-tolerated opioid dose increased from $36 \%$ after the first rotation to $80 \%$ after the fourth rotation (Figure 1). ${ }^{27}$

\section{Initiating opioid rotation and patient assessment}

The choice of the new opioid should be individualized and based on the patient's medical status and history, previous exposure to opioids, access to medication, potential risk for abuse, and other psychosocial factors. ${ }^{3}$ The starting dose of the new opioid is an equally important consideration. Analgesic potency varies among opioids; therefore, equianalgesic dosing tables may be used to calculate the new starting dose (Table 2)..$^{23,24,28,29}$ Although these tables are a reasonable starting point for determining an equianalgesic dose of a new opioid, certain limitations should be acknowledged..$^{28}$ The relative potencies were derived primarily from

Table I Major reasons for opioid rotation ${ }^{3}$

\begin{tabular}{ll}
\hline Major reasons for opioid rotation & \\
\hline Development of intolerable AEs & Patient displays drug-aberrant \\
with current opioid & behavior(s) \\
Lack of analgesia following dose & Patient prefers alternative route \\
escalation & of administration \\
Occurrence of drug-drug & Financial limitations or access \\
interactions & barriers to certain medications \\
\hline
\end{tabular}

Reprinted from J Pain Symptom Manage, vol 38, issue 3, Fine et al, Ad Hoc Expert Panel on Evidence Review and Guidelines for Opioid Rotation. Establishing "best practices" for opioid rotation: conclusions of an expert panel, p418-425, Copyright (2009), with permission from Elsevier.

Abbreviation: AEs, adverse events.

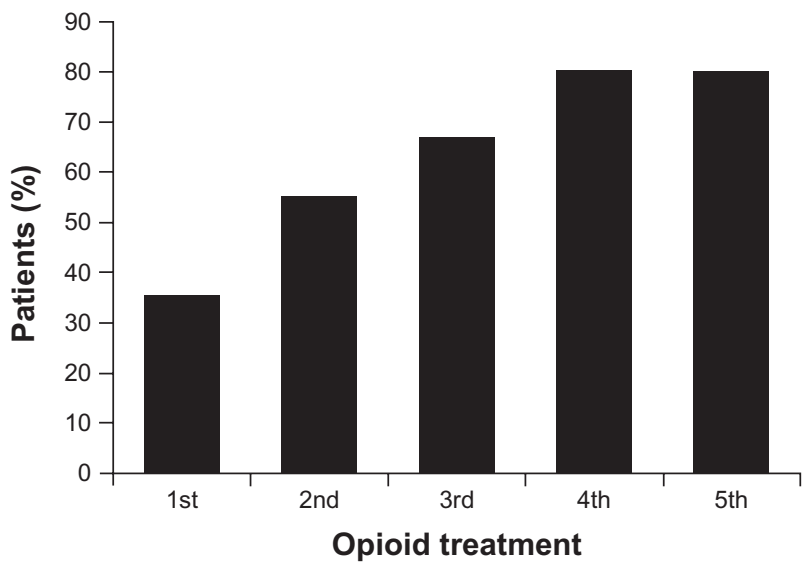

Figure I Cumulative percentage of patients achieving an effective opioid dose with opioid rotation. ${ }^{27}$

Adapted with permission from Quang-Cantagrel et al. Opioid substitution to improve the effectiveness of chronic noncancer pain control: a chart review. Anesth Analg. 2000;90(4):933-937.

studies of patients with acute pain, and often with intravenous opioid administration. ${ }^{28}$ They also do not account for individual patient variability. ${ }^{28}$ It also has been recognized that equianalgesic doses can underestimate the actual potency of the molecule. ${ }^{3}$ An additional dose reduction of $25 \%$ to $50 \%$ below the equianalgesic dose has therefore been recommended (see Patient vignette) to account for underestimated potency and incomplete cross-tolerance among opioids. ${ }^{3}$ Although a more conservative approach may help safeguard against adverse outcomes in patients particularly sensitive to the new opioid, a 50\% additional reduction may not provide adequate analgesia for some patients. For patients undergoing

Table 2 Original equianalgesic dose table ${ }^{28}$

\begin{tabular}{lll}
\hline Medication & \multicolumn{2}{l}{$\begin{array}{l}\text { Equianalgesic (mg) doses, route } \\
\text { of administration }\end{array}$} \\
\cline { 2 - 3 } & $\begin{array}{l}\text { Intramuscular/intravenous/ } \\
\text { subcutaneous }\end{array}$ & Oral \\
\hline Morphine $^{\mathrm{a}}$ & $10 \mathrm{mg}$ & $60 \mathrm{mg}$ \\
Hydromorphone $^{\mathrm{b}}$ & $1.5 \mathrm{mg}$ & $7.5 \mathrm{mg}$ \\
Oxycodone $^{\text {Oxymorphone }}$ & & $20-30 \mathrm{mg}$ \\
Levorphanol $^{\mathrm{C}}$ & $\mathrm{I} \mathrm{mg}$ & $15 \mathrm{mg}$ \\
Methadone $^{\mathrm{d}}$ & $2 \mathrm{mg}$ & $4 \mathrm{mg}$ \\
Fentanyl & $10 \mathrm{mg}$ & $20 \mathrm{mg}$ \\
\hline Notes: & $50-100 \mu \mathrm{g}^{\mathrm{e}}$ & \\
\hline
\end{tabular}

Notes: ${ }^{\text {PPotency estimates relative to the original dose table have undergone }}$ little change; however, the oral morphine dose is often revised to 20 to $30 \mathrm{mg}$, as the original acute dosing data do not apply to chronic opioid therapy; balthough the morphine:hydromorphone equianalgesic potency ratio is as high as $8: 1$ for hydromorphone IR, the equianalgesic potency ratio for hydromorphone ER is $5: 1^{23,24,29}$; 'oxymorphone equianalgesic dose for rectal administration: $10 \mathrm{mg}$; din clinical practice, methadone appears to be more potent than originally estimated, warranting caution during rotation (see text: Rotation to Methadone); ${ }^{\text {edose ratio only }}$ applicable to intravenous and subcutaneous administration.

Reprinted from J Pain Symptom Manage, vol 38, issue 3, Knotkova et al, Opioid rotation: the science and the limitations of the equianalgesic dose table, p426-439, Copyright (2009), with permission from Elsevier. 
rotation to a new opioid, inadequate analgesia can potentially manifest as breakthrough pain or symptoms of withdrawal (concepts discussed in detail below). ${ }^{3}$ An IR opioid may therefore be given as a supplemental analgesic. ${ }^{3}$

From this author's clinical experience, converting patients to $66 \%$ of the previous total daily opioid dose, or a dose reduction of $33 \%$ below the equianalgesic dose, is suggested. In addition, patients can be given an IR opioid for supplemental analgesia, dosed at $33 \%$ of the new total daily opioid dose. In line with the principles of responsible opioid prescribing, the individual clinical decision-making process should be based on a comprehensive patient assessment, including past opioid experience and the agreed upon treatment plan. ${ }^{30}$

Following the initial calculation of the equianalgesic dose, a number of other assessments should be made before administering the new opioid dose. The patient's current pain intensity, side effect profile, and medical status should be assessed, in addition to other medical and psychosocial factors that may affect the outcome of treatment. In certain cases, an additional $15 \%$ to $30 \%$ increase or decrease of the daily opioid dose may be applied (Table 3 ). ${ }^{3}$

\section{Clinical considerations Opioid selection}

As patients managed with chronic opioid therapy likely receive concomitant medications, there is a significant risk of drug-drug interactions. ${ }^{4,31}$ Opioids that undergo cytochrome P450 (CYP450) isoenzyme metabolism have a greater risk of interaction with concomitant medications metabolized by the same CYP450 pathway. ${ }^{4}$ Of the ER or controlledrelease opioids, hydromorphone, morphine, oxycodone, and tapentadol appear to have little to no interaction with the CYP450 pathway, ${ }^{10,12,13,15,19,32}$ indicating a lower risk of drug-drug interactions with certain medications.

While it is not possible to predict who is likely to respond to a particular opioid, the patient's history of opioid exposure may provide important insights. For example, in a patient undergoing a rotation from IR oxycodone to controlled-release oxycodone, there is the potential for a more favorable therapeutic response based on the patient's previously demonstrated tolerability of this molecule. A similar "molecule matching" approach may also be applicable when rotating a patient from hydrocodone to hydromorphone. Hydrocodone is metabolized, in part, to hydromorphone through the CYP450 (2D6) pathway. ${ }^{33}$ Patients previously maintained on hydrocodone, and particularly hydrocodonetreated patients who are CYP2D6 rapid metabolizers,
Table 3 Expert consensus for a two-step approach to opioid rotation $^{3}$

- Calculate the equianalgesic starting dose of the new
opioid using an equianalgesic dosing table
- Apply an additional dose reduction of $25 \%$ to $50 \%$
to the equianalgesic starting dose
O Reduction closer to $50 \%$ if the patient was previously
receiving a relatively high opioid dose, is not
Caucasian, or is elderly, or medically frail
O Reduction closer to $25 \%$ in patients without the
aforementioned characteristics or in patients
changing only the route of administration
- Assess the patient's current pain severity, occurrence
of adverse events, medical status, and other medical or
Psychosocial factors influencing therapeutic efficacy
O Initiate opioid therapy with the starting dose
determined using step I or apply an additional
I5\% to $30 \%$ dose increase or decrease based on
the likelihood of achieving adequate analgesia with
tolerable adverse events and without inducing
withdrawal
Consider providing supplemental opioid analgesia
during the titration process of $5 \%$ to I5\% of the total
daily opioid dose

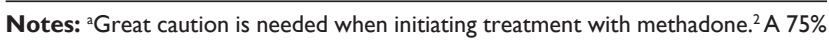
to $90 \%$ additional dose reduction or inpatient monitoring is recommended with an equianalgesic starting dose of $\geq 100 \mathrm{mg} /$ day of methadone $\mathrm{e}^{3}$; ${ }^{\mathrm{b}}$ no additional dose reduction is recommended when rotating to transdermal fentanyl when using the conversion tables provided in the drug's prescribing information.

Reprinted from J Pain Symptom Manage, vol 38, issue 3, Fine et al, Ad Hoc Expert Panel on Evidence Review and Guidelines for Opioid Rotation. Establishing "best practices" for opioid rotation: conclusions of an expert panel, p4I8-425, Copyright (2009), with permission from Elsevier.

theoretically may experience favorable tolerability when converted to hydromorphone. ${ }^{32,34}$ Likewise, patients previously maintained on oxycodone, which is metabolized, in part, to oxymorphone, ${ }^{35}$ may be more likely to respond to a rotation to oxymorphone. The validity of this "molecule matching" approach, however, requires confirmation from systematic studies.

\section{Supplemental analgesia to manage breakthrough pain}

Although breakthrough pain in patients with chronic noncancer pain has not been fully characterized, recent studies show a prevalence of $48 \%$ to $74 \%$ in this patient population, despite having well-controlled baseline persistent pain. ${ }^{36-38}$ Patients report an average of 1 to 2 episodes per day, with a median time to maximum intensity of 1 to 10 minutes and a median episode duration of 45 minutes to 1 hour. ${ }^{37,38}$

Patients undergoing opioid rotation may experience breakthrough pain, and this type of pain should undergo a separate assessment from the patient's baseline persistent pain., 
As previously mentioned, an IR opioid may be provided for supplemental analgesia when initiating a new opioid trial (see Patient vignette). ${ }^{3}$ However, the total daily dose including the primary opioid and the supplemental IR opioid should be considered, given the increased risk of AEs and overdose with high daily doses. ${ }^{21}$

\section{Rotation to methadone}

Additional caution must be taken if rotating a patient's therapy to methadone. ${ }^{2,3}$ Methadone is indicated for the treatment of moderate-to-severe pain that is uncontrolled with non-opioid analgesics. ${ }^{2}$ The 4 - to 8 -hour duration of analgesic effect makes methadone amenable for use in chronic pain management. ${ }^{39}$ However, the elimination halflife of the molecule varies widely across patients and may last up to 59 hours. ${ }^{39}$

In clinical studies, methadone appears to be substantially more potent than previously believed, particularly when rotating from another mu-opioid. ${ }^{40}$ Specifically, methadone has been reported to reverse mu-agonist opioid tolerance, and deaths have been reported following conversion to methadone in patients receiving other chronic opioid therapy. ${ }^{28,41}$ The risk of serious, life-threatening AEs, such as respiratory depression and cardiac arrhythmias, can persist beyond the duration of analgesic effects. ${ }^{39}$ From 1999-2006, there was an approximate 7-fold rise in methadone-related deaths in the US. ${ }^{42}$ An in-depth knowledge of the variable pharmacokinetics and associated risks of methadone is therefore essential, and current guidelines underline the importance of cautious initiation and dose titration. ${ }^{2}$

\section{Managing withdrawal}

Symptoms of withdrawal can manifest following a dose reduction in chronic pain patients who are tolerant to, and physically dependent on, opioids. ${ }^{43}$ Patients who undergo rotation may experience withdrawal due to the additional reduction in the equianalgesic dose, necessitating the ability to recognize and manage associated signs and symptoms. ${ }^{3}$ This can include such autonomic signs as diarrhea, rhinorrhea, and piloerection, as well as central neurologic arousal characterized by sleeplessness, irritability, and psychomotor agitation. ${ }^{43}$ As the dose is individually titrated to adequate analgesia, however, the symptoms of withdrawal can potentially dissipate.

\section{Policies regulating prescription opioid use}

Patients with chronic non-cancer pain require comprehensive treatment, given the common accompaniment of complex comorbidities. ${ }^{2}$ All health care providers managing patients with opioid analgesics should adhere to good prescribing principles to ensure that the benefits outweigh the risks. ${ }^{2}$ This includes, but is not limited to, the ability and resources to assess and manage opioid-related AEs and other risks such as misuse, abuse, and diversion. ${ }^{2}$ Furthermore, compliance with federal and individual state policies governing prescription opioid use is fundamental. ${ }^{44}$

To ensure that the therapeutic benefit outweighs the risks, the FDA recently announced a classwide Risk Evaluation and Mitigation Strategy (REMS) for all long-acting and ER opioids. ${ }^{45}$ Under this program, prescribers will be required to undergo training on appropriate and safe prescribing practices. ${ }^{45}$ Since opioid rotation requires the knowledge to safely prescribe a range of opioid formulations, education provided through this REMS should act as a complementary measure. Patients will also receive materials and undergo counseling on safe use. ${ }^{45}$ Importantly, this information will include points on proper opioid disposal. ${ }^{45}$ As rotation from one opioid to another may leave unused doses, patients should be advised to flush their unused medication to avoid the risk of accidental exposure. ${ }^{46}$

Although not currently implemented, future legislation may require a prescriber to undergo training as part of US Drug Enforcement Administration registration. ${ }^{47}$ Preemptive and active participation in classwide REMS for ER opioids is therefore encouraged.

\section{Conclusion}

Current scientific knowledge limits the ability to predict which patient will respond optimally to which opioid analgesic. Opioid rotation is therefore a necessary practice in the management of chronic non-cancer pain to achieve therapeutic efficacy with the lowest possible dose. Even patients who respond favorably to initial opioid therapy may require rotation to a new opioid over time to maintain adequate analgesia. Importantly, this practice also minimizes the risks of AEs and overdose associated with frequent dose escalations and higher daily opioid doses. Clinical judgment based on the individual patient should be used when determining the new opioid for rotation, and careful attention should be taken to individualize the starting dose. Guided by state policies and responsible prescribing practices, opioid rotation can be safely and effectively implemented in clinical practice.

\section{Acknowledgments}

Technical editorial and writing assistance for the preparation of this manuscript was provided by Meg Church, Synchrony 
Medical, LLC, West Chester, PA. Funding for this support was provided by Mallinckrodt Inc, a Covidien company, Hazelwood, MO.

\section{Disclosure}

Dr Nalamachu discloses that he was a principal investigator for an extended-release hydromorphone trial conducted by Neuromed. He has also received research grants from Mallinckrodt Inc, a Covidien company, and is a member of their Speakers Bureau.

\section{References}

1. Galer BS, Coyle N, Pasternak GW, Portenoy RK. Individual variability in the response to different opioids: report of five cases. Pain. 1992; 49(1):87-91.

2. Chou R, Fanciullo GJ, Fine PG, et al. Opioid treatment guidelines: clinical guidelines for the use of chronic opioid therapy in chronic noncancer pain. J Pain. 2009;10(2):113-130.

3. Fine PG, Portenoy RK. Ad Hoc Expert Panel on Evidence Review and Guidelines for Opioid Rotation. Establishing "best practices" for opioid rotation: conclusions of an expert panel. J Pain Symptom Manage. 2009;38(3):418-425.

4. Slatkin NE. Opioid switching and rotation in primary care: implementation and clinical utility. Curr Med Res Opin. 2009; 25(9):2133-2150.

5. Mercadante S. Opioid rotation for cancer pain: rationale and clinical aspects. Cancer: 1999;86(9):1856-1866.

6. Pan L, Xu J, Yu R, Xu MM, Pan YX, Pasternak GW. Identification and characterization of six new alternatively spliced variants of the human mu opioid receptor gene, Oprm. Neuroscience. 2005;133(1): 209-220.

7. Pasternak GW. Incomplete cross tolerance and multiple mu opioid peptide receptors. Trends Pharmacol Sci. 2001;22(2):67-70.

8. Eckhardt K, Li S, Ammon S, Schänzle G, Mikus G, Eichelbaum M. Same incidence of adverse drug events after codeine administration irrespective of the genetically determined differences in morphine formation. Pain. 1998;76(1-2):27-33.

9. Russell RD, Chang KJ. Alternated delta and mu receptor activation: a stratagem for limiting opioid tolerance. Pain. 1989;36(3):381-389.

10. Exalgo [package insert]. Hazelwood, MO: Mallinckrodt Inc, a Covidien company; 2010.

11. Embeda [package insert]. Bristol, TN: King Pharmaceuticals; 2009.

12. Oxycontin [package insert]. Stamford, CT: Purdue Pharma LP; 2010.

13. Avinza [package insert]. Bristol, TN: King Pharmaceuticals Inc; 2008.

14. Opana ER [package insert]. Chadds Ford, PA: Endo Pharmaceuticals Inc; 2008 .

15. Kadian [package insert]. Morristown, NJ: Actavis Elizabeth LLC; 2010.

16. MS Contin [package insert]. Stamford, CT: Purdue Pharma LP; 2009.

17. Oramorph SR [package insert]. Newport, KY: Xanodyne Pharmaceuticals Inc; 2006.

18. Duragesic [package insert]. Raritan, NJ: PriCara, Division of Ortho-McNeil-Janssen Pharmaceuticals Inc; 2006.

19. Nucynta ER [package insert]. Titusville, NJ: Janssen Pharmaceuticals Inc; 2011.

20. Gourlay DL, Heit HA, Almahrezi A. Universal precautions in pain medicine: a rational approach to the treatment of chronic pain. Pain Med. 2005;6(2):107-112.

21. Bohnert AS, Valenstein M, Bair MJ, et al. Association between opioid prescribing patterns and opioid overdose-related deaths. JAMA. 2011; 305(13):1315-1321.
22. Dunn KM, Saunders KW, Rutter CM, et al. Opioid prescriptions for chronic pain and overdose: a cohort study. Ann Intern Med. 2010; 152(2):85-92.

23. Hale M, Khan A, Kutch M, Li S. Once-daily OROS hydromorphone ER compared with placebo in opioid-tolerant patients with chronic low back pain. Curr Med Res Opin. 2010;26(6):1505-1518.

24. Palangio M, Northfelt DW, Portenoy RK, et al. Dose conversion and titration with a novel, once-daily, OROS osmotic technology, extended-release hydromorphone formulation in the treatment of chronic malignant or nonmalignant pain. J Pain Symptom Manage. 2002;23(5):355-368.

25. US Food and Drug Administration. Questions and answers about oral prescription acetaminophen products to be limited to $325 \mathrm{mg}$ per dosage unit. Available from: http://www.fda.gov/Drugs/DrugSafety/ InformationbyDrugClass/ucm239871.htm. Accessed October 7, 2011.

26. US Food and Drug Administration. Acetaminophen overdose and liver injury - background and options for reducing injury. Available from: http://www.fda.gov/downloads/AdvisoryCommittees/ CommitteesMeetingMaterials/Drugs/DrugSafetyandRiskManagement AdvisoryCommittee/UCM164897.pdf. Accessed November 1, 2011.

27. Quang-Cantagrel ND, Wallace MS, Magnuson SK. Opioid substitution to improve the effectiveness of chronic noncancer pain control: a chart review. Anesth Analg. 2000;90(4):933-937.

28. Knotkova H, Fine PG, Portenoy RK. Opioid rotation: the science and the limitations of the equianalgesic dose table. J Pain Symptom Manage. 2009;38(3):426-439.

29. Mahler DL, Forrest WH Jr. Relative analgesic potencies of morphine and hydromorphone in postoperative pain. Anesthesiology. 1975;42(5): 602-607.

30. Smith H, Fine P, Passik S. Opioid Risk Management: Tools and Tips. New York: Oxford University Press, Inc; 2009.

31. Parsells Kelly J, Cook SF, Kaufman DW, Anderson T, Rosenberg L, Mitchell AA. Prevalence and characteristics of opioid use in the US adult population. Pain. 2008;138(3):507-513.

32. Smith HS. Opioid metabolism. Mayo Clin Proc. 2009;84(7): 613-624.

33. Cone EJ, Darwin WD, Gorodetzky CW, Tan T. Comparative metabolism of hydrocodone in man, rat, guinea pig, rabbit, and dog. Drug Metab Dispos. 1978;6(4):488-493.

34. Otton SV, Schadel M, Cheung SW, Kaplan HL, Busto UE, Sellers EM. CYP2D6 phenotype determines the metabolic conversion of hydrocodone to hydromorphone. Clin Pharmacol Ther. 1993;54(5): 463-472.

35. Lalovic B, Phillips B, Risler LL, Howald W, Shen DD. Quantitative contribution of CYP2D6 and CYP3A to oxycodone metabolism in human liver and intestinal microsomes. Drug Metab Dispos. 2004; 32(4):447-454.

36. Manchikanti L, Singh V, Caraway DL, Benyamin RM. Breakthrough pain in chronic non-cancer pain: fact, fiction, or abuse. Pain Physician. 2011;14(2):E103-E117.

37. Portenoy RK, Bennett DS, Rauck R, et al. Prevalence and characteristics of breakthrough pain in opioid-treated patients with chronic noncancer pain. J Pain. 2006;7(8):583-591.

38. Portenoy RK, Bruns D, Shoemaker B, Shoemaker SA. Breakthrough pain in community-dwelling patients with cancer pain and noncancer pain, part 1: prevalence and characteristics. J Opioid Manag. 2010;6(2): 97-108.

39. US Food and Drug Administration. Information for healthcare professionals: methadone hydrochloride. Rockville, MD: US Food and Drug Administration; 2006.

40. Bruera E, Pereira J, Watanabe S, Belzile M, Kuehn N, Hanson J. Opioid rotation in patients with cancer pain. A retrospective comparison of dose ratios between methadone, hydromorphone, and morphine. Cancer. 1996;78(4):852-857.

41. Davis AM, Inturrisi CE. d-Methadone blocks morphine tolerance and N-methyl-D-aspartate-induced hyperalgesia. J Pharmacol Exp Ther. 1999;289(2):1048-1053. 
42. Warner M, Chen LH, Makuc DM. Increase in fatal poisonings involving opioid analgesics in the United States, 1999-2006. NCHS Data Brief. 2009;(22):1-8.

43. Savage SR, Joranson DE, Covington EC, Schnoll SH, Heit HA, Gilson AM. Definitions related to the medical use of opioids: evolution towards universal agreement. J Pain Symptom Manage. 2003;26(1): 655-667.

44. Gilson AM, Joranson DE, Maurer MA. Improving state pain policies: recent progress and continuing opportunities. CA Cancer J Clin. 2007; 57(6):341-353.

45. US Food and Drug Administration. Post-approval REMS notification letter. Available from: http://www.fda.gov/downloads/Drugs/ DrugSafety/InformationbyDrugClass/UCM251595.pdf. Accessed July 29, 2011.
46. US Food and Drug Administration. Disposal of unused medicines: what you should know. Available from: http://www.fda.gov/ Drugs/ResourcesForYou/Consumers/BuyingUsingMedicineSafely/ EnsuringSafeUseofMedicine/SafeDisposalofMedicines/ucm186187. htm. Accessed September 12, 2011.

47. US Food and Drug Administration. Questions and answers: FDA requires a Risk Evaluation and Mitigation Strategy (REMS) for longacting and extended-release opioids. Available from: http://www.fda. gov/Drugs/DrugSafety/InformationbyDrugClass/ucm251752.htm. Accessed July 29, 2011.

\section{Publish your work in this journal}

The International Journal of General Medicine is an international, peer-reviewed open-access journal that focuses on general and internal medicine, pathogenesis, epidemiology, diagnosis, monitoring and treatment protocols. The journal is characterized by the rapid reporting of reviews, original research and clinical studies across all disease areas.

\section{Dovepress}

A key focus is the elucidation of disease processes and management protocols resulting in improved outcomes for the patient.The manuscript management system is completely online and includes a very quick and fair peer-review system. Visit http://www.dovepress.com/ testimonials.php to read real quotes from published authors.

Submit your manuscript here: http://www.dovepress.com/international-journal-of-general-medicine-journal 